\title{
CUIDADOR INFORMAL: COMO SÃO VISTOS PELOS PROFISSIONAIS DE SAÚDE?
}

\section{ARTIGO ORIGINAL}

MARIANO, Graziela Pereira ${ }^{1}$ SANTOS, Irenilda Ângela dos ${ }^{2}$

MARIANO, Graziela Pereira. SANTOS, Irenilda Ângela dos. Cuidador Informal: como são vistos pelos profissionais de saúde?. Revista Científica Multidisciplinar Núcleo do Conhecimento. Ano 07, Ed. 01, Vol. 04, pp. 224-253. Janeiro de 2022. ISSN: 2448-0959,

Link

de

acesso:

\section{https://www.nucleodoconhecimento.com.br/saude/cuidador-informal}

\section{RESUMO}

A saúde pública brasileira aponta para a necessidade de mudanças, que, entre outros fatores, dependem de uma atenção humanizada na perspectiva do cuidado integral da saúde dos internados e de seus cuidadores. Na saúde, deve-se considerar que a construção da relação entre sujeitos (paciente e cuidador) é um instrumento poderoso para que essa mudança ocorra. Este artigo tem como objetivo geral identificar a concepção dos profissionais do Hospital Universitário Júlio Muller quanto ao cuidado com a saúde do cuidador informal, para tanto o trabalho visa responder à seguinte pergunta problema: qual é a concepção de saúde e doença, sob a ótica dos profissionais de saúde, e as respectivas ações (ou atendimento) ofertadas por esses profissionais ao cuidador informal no período de internação do paciente? Como metodologia, foi utilizada a análise qualitativa, por meio de entrevista semiestruturada com profissionais de saúde que atuam na clínica médica do HUJM. Parte-se da premissa de que o cuidador informal merece ser considerado como um membro integrante do processo de cuidados, em que seu bem-estar e promoção também sejam levados em consideração, assim como a prevenção de situações extremas requer, por parte dos profissionais de saúde, uma atenção

\footnotetext{
${ }^{1}$ Graduada em Serviço Social.

${ }^{2}$ Doutora em Desenvolvimento Sustentável pela Universidade de Brasília.
} 
particular, uma vez que deles também depende a recuperação dos pacientes internados. No entanto, da análise realizada no HUJM, foi possível constatar que existe uma falta de articulação entre o hospital e as possibilidades para a oferta de serviços de cuidador, que leva à necessidade de se rever questões de ordem estruturais e de comunicação entre o corpo hospitalar, os pacientes e os cuidadores.

Palavras-chave: Cuidado Integral, Cuidador Informal, Humanização.

\section{INTRODUÇÃO}

O presente artigo faz parte da pesquisa "Formação e Trabalho em Serviço Social: desafios da intervenção e pesquisa sobre as determinações sociais em saúde, organização e luta de usuários e trabalhadores para assegurar os direitos à saúde", aprovado pelo Comitê de Ética, sob o parecer n. ${ }^{\circ} 723.606$, dos alunos de graduação em Serviço Social que realizaram estágio no Hospital Universitário Júlio Muller da Universidade Federal de Mato Grosso (HUJM/UFMT).

Este estudo tem por intuito conhecer sobre a concepção dos profissionais de saúde da clínica médica do HUJM em relação ao cuidado com a saúde do cuidador informal no período de internação. Cuidar é uma prática milenar e universal, e, quando se fala nas ações do cuidado com a saúde, verifica-se, no local de estudo, um interesse e uma preocupação com o tratamento e recuperação de outra pessoa, conduzindo esse objetivo a partir de determinadas práticas.

Atualmente, com a busca de uma sociedade mais humanizada na prestação dos cuidados com a saúde, o papel do cuidador tornou-se imprescindível, pois contribui, conjuntamente com outros prestadores de cuidados com a saúde, para o bem-estar físico, psicológico e emocional do doente (FIGUEIREDO; DIAS; OLIVEIRA, 2014).

Nesse sentido, o cuidado ultrapassa a dimensão biológica e deve também receber atenção a sua saúde pessoal do cuidador, considerando-se que a atividade profissional unicamente técnica implica na organização eficiente do cuidado. Dessa forma, é primordial que se ofereçam condições de infraestrutura e de suporte para 
que familiares e/ou amigos possam efetivamente exercer o papel de cuidadores informais. É necessário que, além de conhecer as necessidades de cuidado da pessoa dependente, também se conheça e valorize a situação dessas famílias: suas demandas, valores e práticas socioculturais, não se limitando à condição biológica.

O conhecimento do perfil dos cuidadores e de suas dificuldades no processo de cuidar permite aos profissionais da saúde planejar, implantar políticas e programas públicos de suporte social e à família, voltados à realidade do cuidador (ROCHA JúNIOR et al., 2011).

Nessa perspectiva, o objetivo geral deste artigo é identificar a concepção dos profissionais do Hospital Universitário Júlio Muller quanto ao cuidado com a saúde do cuidador informal. Para alcançar tal êxito, buscou-se responder à seguinte pergunta-problema: qual é a concepção de saúde e doença, sob a ótica dos profissionais de saúde, e as respectivas ações (ou atendimento) ofertadas por esses profissionais ao cuidador informal no período de internação do paciente?

Acredita-se que este estudo poderá contribuir para a reflexão no âmbito da gestão e da assistência, ampliando o debate da política de saúde com relação ao cuidador informal. Para tanto, utilizou-se como metodologia a abordagem qualitativa, de caráter exploratório e descritivo, com o intuito de averiguar a concepção de saúde e doença na ótica dos profissionais, levantar quais as ações (ou atendimento) o profissional de saúde oferece ao cuidador no período de internação e identificar a opinião do profissional de saúde no HUJM com relação à necessidade do cuidador para o paciente internado.

\section{REFERENCIAL TEÓRICO}

O movimento de reforma sanitária foi um marco para implementação do Sistema Único de Saúde (SUS), que imprimiu os fundamentos da política de saúde, tendo como pressuposto sua defesa como um direito de todos e dever do Estado. 
Logo, saúde é acesso à educação, ao lazer, à cultura, à renda, ao trabalho, à assistência social, ao esporte, à alimentação, à habitação, dentre outros, propiciando melhores condições de vida e de trabalho ao cidadão. Com base nessa concepção, o SUS se consolidou, a partir da Lei n. ${ }^{\circ} 8.080 / 1990$, tornando-se um marco para as melhorias e avanços no aparato legal e institucional da saúde pública brasileira, pautado nos princípios de universalidade, equidade e integralidade das ações.

Entre as principais propostas da reforma sanitária, destaca-se o conceito ampliado de saúde, que rompeu com o paradigma biológico de ser apenas a ausência de doença. Nesse sentido, a política de humanização retoma a agenda da reforma sanitária, pois aponta para a necessidade de problematizar os modos de fazer existentes nas práticas de saúde, com a valorização do cotidiano e do concreto, sem idealizá-las, mas tornando eficientes tanto a relação dos trabalhadores e usuários do SUS quanto a reorganização e ampliação dos serviços ofertados. Na política de humanização, o tema da participação em saúde assume novos contornos, ampliando-se na direção da inclusão protagonista e corresponsável dos sujeitos envolvidos no processo de produção de saúde. Assim, entende-se que os atendimentos devem se dar com base na troca de saberes e no diálogo (incluindo os pacientes e seus familiares), respeitando e valorizando as necessidades sociais, os desejos e os interesses de todos (OLIVEIRA; CUTOLO, 2012).

No ano de 2003, o Ministério da Saúde criou a Política Nacional de Humanização (PNH), também chamada de Humaniza SUS, com a prática da Clínica Ampliada como uma de suas diretrizes, a partir da construção de processos de comunicação e vínculos que permitam dar passagem aos interesses, necessidades e desejos dos sujeitos dessa relação. Essas diretrizes se apoiam em três princípios: (i) a ampliação da transversalidade com abertura comunicacional daquele que é assistido, junto aos saberes diversos que possibilitam a capacidade de interferência entre os sujeitos e suas subjetividades; (ii) a inseparabilidade entre gestão e atenção e (iii) a aposta na autonomia dos sujeitos individuais e coletivos, tanto na gestão (dos serviços e das práticas de atenção à saúde) como na corresponsabilização do cuidado (de si e dos outros) nos processos de trabalho. 
No campo da saúde no Brasil, as mudanças estão ligadas à compreensão de saúde definida pela Constituição Federal de 1988 (CF/88). Isso se deve ao fato de que a mudança das relações entre trabalhador da saúde, paciente e cuidador não pode ser compreendida como decorrente apenas de técnicas, mas também como resultado das questões subjetivas que emergem das questões sociais, culturais e políticas. A $\mathrm{CF} / 88$ estabeleceu uma nova base jurídico-legal para a política de saúde, definindoa como um direito de qualquer cidadão, logo, um dever do Estado, compreendendo que a saúde corresponde a um enunciado mais amplo que a ausência de doenças.

Zeni e Cutolo (2011) definem a humanização como as atitudes que respeitam a integralidade do sujeito, recusando-se a reduzi-lo à estrutura biológica, considerando ações menos simplistas e fragmentadas. Nesses termos, pode-se, então, dizer que a humanização é uma atuação interdisciplinar, não associada a um momento específico da ação, mas que permeia todas as outras em saúde.

Dessa forma, a PNH torna-se uma referência para a construção de práticas de saúde que, de fato, sejam capazes de produzir novos sentidos entre sujeitos, servindo também como uma ferramenta de mobilização social, não apenas de denúncia e de reivindicação de direitos, mas de afirmação, que considera as diferenças e singularidades no enfrentamento dos desafios que a saúde tem pela frente.

Oliveira e Cutolo (2012) demonstram a proximidade existente entre a humanização e o princípio da integralidade, sendo que este vai muito além de uma diretriz, uma vez que a humanização se caracteriza por condutas desenvolvidas na relação entre sujeitos e assegura uma abordagem integral. Para Viegas e Penna (2013), ela nos remete à interdisciplinaridade do cuidado, de enxergar o indivíduo como um todo, considerando as relações de serviços entre os diferentes níveis de atendimento e das relações no trabalho em equipe.

Nesse sentido, Pinheiro e Mattos (2005, p. 256) concebem a integralidade como: "[...] um conjunto articulado de ações e serviços de saúde, preventivos e curativos, individuais e coletivos, em cada caso, nos níveis de complexidade do sistema." As 
autoras relatam, ainda, que a integralidade se constitui como ato em saúde nas vivências cotidianas dos sujeitos nos serviços em locais de saúde e são essas experiências que produzem transformações na vida das pessoas, cujas práticas eficazes de cuidado superam os modelos idealizados. Já Oliveira e Cutolo (2012) argumentam que a integralidade deve ser entendida como um valor a ser sustentado e defendido pelas práticas dos profissionais de saúde, pautados na maneira como estes atendem os usuários que os procuram e guiados por uma visão ampliada das necessidades dos sujeitos.

Em relação às mudanças e transformações necessárias à área da saúde, no tocante à criação de políticas fundamentadas na compreensão do conceito ampliado de saúde, destacam- se a necessidade de fortalecer as mudanças no modelo de atenção hegemônico, a importância do trabalho em equipe e de refletir sobre os processos de trabalho, intersetorialidade e interdisciplinariedade, com condições indispensáveis para concretizar tais modificações e atribuir qualificação no sentido do cuidado integral com a saúde das pessoas (SILVA, 2013).

Sendo assim, pode-se concluir que a humanização é consequência da aplicação do princípio da integralidade, uma vez que só se produz atitudes humanizadas em saúde a partir de uma concepção ampliada do processo saúde-doença. Tudo isso nos leva a perceber que o grande desafio está em mudar a forma de ver e pensar a saúde e a doença.

Quanto ao cuidado com a saúde, Feuerwerker e Cecílio (2007, p. 967) apontam que "o cuidado recebido pelo paciente no hospital é resultante de vários cuidados parciais que se complementam a partir da interação entre os vários profissionais de saúde". A esse respeito, importa dizer que a mudança de ver e pensar o cuidado à saúde deve estar apoiada nos processos de produção e reprodução social, juntamente com a dimensão subjetiva, que também influencia no cuidado.

O processo de cuidado é realizado por profissionais de diversas áreas e abrange vários aspectos da condição física e social de doentes e cuidadores informais, por isso o cuidado deve ser feito por uma equipe interdisciplinar de profissionais e, 
sempre que possível, envolvendo os familiares e amigos (FIGUEIREDO; DIAS; OLIVEIRA, 2014).

O serviço social, na perspectiva da atenção integral, estrutura seu processo de trabalho junto às equipes interdisciplinares de saúde, com uma abordagem individual e coletiva, e planeja sua ação na perspectiva do direito e da ampliação da cidadania. (MOURÃO et al., 2006). No entanto, os saberes comuns às diversas profissões e os de responsabilidade específica de cada profissão, quando articulados, são úteis para atender às necessidades dos sujeitos de maneira mais humanizada, assim, a forma como se articulam as práticas dos trabalhadores de saúde, dos cuidadores e do paciente que recebe cuidados aumentam ou diminuem a relação do trabalho em equipe.

As relações entre o usuário e os profissionais de saúde ocorrem de modos diferentes, "dependendo do cenário, do grau de sofrimento, da instabilidade clínica, do risco de morte", que dificultam as possibilidades dos usuários em efetivar sua autonomia e dos trabalhadores usar sua autoridade (FEUERWERKER, 2011, p. 1). Essas são, então, as bases para se construir relações de responsabilização e resolubilidade entre trabalhadores de saúde e usuários, de maneira que possam interferir significativamente no atendimento e sejam capazes de oferecer condições de benefícios ao usuário.

O usuário se orienta a partir de vários aspectos: seus saberes, história de vida, valores, religião, trabalho, mídia, suas possibilidades, desejos, dificuldades, fantasias, medos etc. Os profissionais de saúde, dependendo do modo e do recorte que utilizam em sua aproximação, nem sequer consideram esses aspectos, os quais, em sua maioria, são mencionados pelos usuários junto à "queixa" e que, certamente, são fundamentais para as avaliações, definições, decisões e condutas a serem tomadas (FEUERWERKER, 2011).

Para Merhy (1998), os indivíduos, quando buscam os serviços de saúde, esperam obter uma relação de confiança, com a certeza de que seu problema será entendido e que os profissionais terão o compromisso de fazer tudo que puder para defender 
sua vida. Por outro lado, os profissionais de saúde esperam responder às expectativas de seus pacientes, no entanto, nem sempre reconhecem as suas necessidades e a forma com que alinharão os anseios dos pacientes com a aplicabilidade da técnica do cuidado.

Outro aspecto muito importante no que tange aos usuários são os seus acompanhantes, especialmente quando se trata de usuários hospitalizados, pois, de acordo com a PNH (BRASIL, 2007, p. 3), "o acompanhante é o representante da rede social da pessoa internada, que a acompanha durante toda sua permanência nos ambientes de assistência à saúde."

Alguns autores conceituam o acompanhante como cuidador, Rafacho e Oliver (2010, p. 42), por exemplo, o define como a "pessoa que presta cuidados fundamentais a alguém que apresente algum tipo de dependência, de forma parcial ou integral." Gonçalves (2007) afirma que a presença de um acompanhante durante a internação ajuda o usuário hospitalizado a manter os laços sociais e, com isso, contribui para a sua recuperação.

Com a participação da família nos cuidados em relação à saúde, a autora verifica dois aspectos muito importantes: o doente, na presença de um acompanhante, sente maior ligação com o seu ambiente natural e familiar; por outro lado, a família, que tem maior acesso à informação a respeito da saúde do doente, das intervenções realizadas e da evolução do quadro de saúde, pode continuar a cuidar dele como se não estivesse internado, o que contribui para diminuir a ansiedade e o estresse do prestador de cuidados (FIGUEIREDO; DIAS; OLIVEIRA, 2014).

Cuidar de uma pessoa dependente por um longo período acarreta tensões e estresse devido ao aumento das responsabilidades, à sobrecarga econômica, ao cansaço físico e emocional, além da questão relacionada à adequação das rotinas e das relações sociais do cuidador. A par dessa sobrecarga, o cuidador informal tem que ter capacidade emocional para lidar com a dependência do seu ente querido, acrescentando o fato de que, por vezes, esse cuidador também pode vir a ter problemas de saúde ou, ainda, estes serem agravados com o ato de cuidar. Assim, 
quem cuida deve zelar de si mesmo para melhor tratar do outro, ou seja, temos de cuidar de quem cuida, equacionando a família no seu duplo papel de apoiante e apoiada (FIGUEIREDO; DIAS; OLIVEIRA, 2014).

Quando se trata do termo cuidador, há que destacar que existe ainda uma diferença entre cuidador formal e informal. Por cuidador formal, Oliveira, Queirós e Guerra (2007, p. 18) entendem o "profissional de saúde que assume formalmente o exercício de uma profissão, pela qual optou de livre vontade e para qual teve preparação acadêmica e profissional.", e, como cuidador informal, o "familiar ou amigo que é solicitado a assegurar a maior parte dos cuidados que o doente requer quando retorna ao contexto familiar."

Pereira (2011) define-o não apenas como a pessoa que presta cuidados no ambiente, mas o familiar, amigo ou vizinho que presta cuidados ao usuário desde o momento da internação e que não recebe qualquer remuneração pelo trabalho desenvolvido. Para a autora, esse conceito refere-se ao "cuidador principal, (...) que presta a maior parte dos cuidados e apoio diário à pessoa doente e que requer ajuda para o desenvolvimento das atividades da vida diária" (PEREIRA, 2011, p. 37). Assim, a definição de cuidador informal surge em contraposição aos profissionais de saúde, que assumem formalmente o exercício da profissão para qual tiveram formação acadêmica.

Estudos de Sanches et al. (2013, p. 69) sobre o acompanhante em um hospital público apontam que a "integração a um ambiente que propicie conforto, segurança e afetividade, além de assistência é então indispensável para a promoção e a recuperação da saúde individual e coletiva". Esse ambiente, na quase totalidade dos casos, requer a existência de discussões a respeito de como ampliar a dinâmica de cuidado na recuperação da saúde do paciente cuidado.

O cuidador tem um importante papel de ligação entre a equipe de saúde e a pessoa cuidada, executando tarefas necessárias, entretanto, necessita mais que isso, pois, da mesma maneira que o doente, o cuidador é usuário do serviço de saúde e requer atenção específica, inclusive no cuidado. 
Assim, necessário se faz que as atividades do cuidador sejam planejadas junto aos profissionais de saúde e familiares, devendo ficarem claras as informações para todos sobre quais são as ações que o cuidador pode e deve desempenhar. É bom escrever as rotinas e quem se responsabiliza pelas tarefas, bem como a equipe deixar claro ao cuidador sobre quais procedimentos ele não pode, não deve fazer e quando é necessário chamar os profissionais de saúde. As ações serão planejadas e executadas de acordo com as necessidades da pessoa a ser cuidada, dos conhecimentos e das disponibilidade do cuidador (BRASIL, 2008).

Pereira (2011) demonstra, em sua pesquisa, que os cuidadores informais apresentam distúrbios do sono pelo fato de não possuírem horário determinado para o descanso e dormirem de maneira inadequada. Com isso, ao cuidar do outro, deixam de cuidar de si mesmos, sendo acometidos por problemas de perda de peso, cefaleias e alterações nas relações conjugais e financeiras.

O SUS preconiza, como objetivos, para a presença dos cuidadores informais, buscar a hospitalização humanizada e a inclusão da família no acesso aos bens e serviços, tendo por variável a perspectiva teórico-crítica do processo saúde/doença. Para tanto, faz-se necessário que toda a equipe (usuários, trabalhadores e gestores) seja educada para essa prática.

$\mathrm{Na}$ prática, o que se compreende é que os serviços de saúde se encontram constituídos ao redor do enfermo, sendo que o cuidador se dispõe numa posição pouco importante ou também designada como marginal. Nessa lógica, os cuidadores são encarados como recursos e, consequentemente, as intervenções dos profissionais de saúde são orientadas no sentido da manutenção desse papel (PEREIRA, 2011).

A equipe de saúde deve, então, em primeira instância, orientar suas intervenções além das capacidades físicas e patológicas, englobando as questões psíquicas do cuidador e do internado, bem como a condição socioeconômica e de moradia, pois nenhuma intervenção resultará em benefício para o doente se o cuidador não for relevante e devidamente integrado no processo de cuidados. 
O cuidador informal merece ser considerado como parte integrante do processo de cuidado, considerando seu bem-estar e sua promoção, assim como a prevenção de situações extremas, em virtude disso, requer, por parte dos profissionais de saúde, uma atenção particular, uma vez que deles dependem os doentes de que cuidam (PEREIRA, 2011). Logo, o cuidador também precisa ser enxergado como sujeito portador de direitos, que necessita ser cuidado, mantendo, com a equipe formal, uma relação menos austera e mais positiva, sentindo-se à vontade para esclarecer dúvidas e obter informações (BRASIL, 2011).

Assim, o que se espera é a constituição de uma aliança entre os profissionais e os cuidadores, que, apesar de alguns profissionais já possuírem qualificação e habilidades para promover apoio e autonomia aos doentes e cuidadores, carecem de um referencial teórico o qual oriente a sua prática.

\section{MÉTODOS E TÉCNICAS}

O estudo foi realizado no Hospital Universitário Júlio Muller, localizado no município de Cuiabá, estado de Mato Grosso. É um hospital público, gratuito, que atende somente usuários(as) referenciados(as) pelo SUS. O regime de atendimento é ambulatorial e de internação, possuindo quatro áreas básicas: Clínica Médica, Cirúrgica, Ginecológica/Obstétrica e Pediatria.

Para este artigo, foram delimitados como colaboradores os profissionais que atuam na clínica médica, por ser este um estudo que se propõe a dar continuidade à pesquisa $A$ (in) visibilidade do cuidador na política de saúde: um percurso desses sujeitos no Hospital Universitário Júlio Muller em Cuiabá-MT. A população em estudo foi composta por enfermeiros, médicos residentes, médicos docentes e internos de medicina, nutricionistas, psicólogos e assistentes sociais.

As fontes primárias se caracterizaram mediante a aplicação de entrevista com os 19 profissionais que atuam na clínica médica no HUJM, destes, um total de 18 aceitou participar, sendo dois técnicos de enfermagem, três chefes de enfermagem, dois residentes de enfermagem, dois residentes de nutrição, dois residentes de 
psicologia, dois residentes de serviço social, um professor de medicina, dois residentes de medicina e dois internos de medicina. À época da pesquisa, existiam dois chefes de enfermagem por período na clínica médica. Assim, optou-se por selecionar de forma aleatória um chefe de enfermagem por período: matutino, vespertino e noturno.

Considerando as características dos profissionais lotados na referida clínica, trata-se de servidores com vínculos diferenciados: alunos, docentes e técnicos administrativos. Além disso, existem profissionais efetivados por concurso público, cedidos da Secretaria Estadual de Saúde, celetistas e contratados.

As entrevistas foram realizadas com uso de roteiro e questões abertas, no período entre os meses de fevereiro e março de 2016, após a realização do pré-teste e ajuste do instrumental. Segundo Minayo (2010, p. 157), a entrevista semiestruturada provoca "[...] as várias narrativas possíveis das vivências que o entrevistador vai avaliar; as interpretações que o entrevistado emite sobre elas e sua visão sobre as relações sociais envolvidas nessa ação".

Para assegurar o sigilo, os entrevistados foram convidados a participar da pesquisa na sala do posto de enfermagem na clínica médica, sob os preceitos da ética em pesquisa, normatizados pela Resolução n.-9 466, de 12 de dezembro de 2012, do Conselho Nacional de Saúde, sendo que, no texto, são identificados por ordem decimal. Autorizadas e assinadas, as entrevistas foram gravadas e depois transcritas na íntegra, sendo apresentadas e analisadas na sequência. A dificuldade enfrentada para a realização das entrevistas no setor decorreu do fato dos profissionais da medicina não disponibilizarem de horário para realizar a sua aplicação.

Esta pesquisa teve como referência o estudo com abordagem descritiva e análise qualitativa, que, para Gil (2012, p. 27-28):

[...] o estudo descritivo tem por objetivo primordial a descrição das características de determinada população ou fenômeno ou o estabelecimento de relação entre variáveis, permitindo assim maior familiaridade com o objeto, 
com vista a torná-lo mais explícito, [...] habitualmente envolvem levantamento bibliográfico e documental, entrevistas não padronizadas e estudos de casos.

No que se refere à análise qualitativa, Minayo (2010, p. 57) afirma que se trata do estudo "[...] da história, das relações, das representações, das crenças, das percepções e das opiniões, produto das interpretações que os humanos fazem a respeito de como vivem, constroem seus artefatos e a si mesmos, sentem e pensam." Assim, a análise qualitativa permite compreender e visualizar os processos sociais e a lógica interna de um grupo, dando base para a construção de novas abordagens durante a investigação.

\subsection{CATEGORIZAÇÃO E ANÁLISE DOS DADOS LEVANTADOS}

Foram utilizadas as seguintes variáveis para categorização dos participantes deste estudo: gênero; área de atuação; vínculo da atividade laboral do participante com o hospital; se possui ou está realizando curso de pós-graduação; se realizou algum curso de capacitação pelo hospital; a carga horária semanal de trabalho e se trabalha em outra instituição além do hospital. Os dados foram organizados e apresentados na tabela 1 a seguir.

Tabela 1 - Distribuição dos participantes da entrevista segundo o perfil sociodemográfico

\begin{tabular}{|l|l|l|l|}
\hline Variáveis & Caracterização & Número & $\%$ \\
\hline Gênero & Feminino & 14 & 78,00 \\
\hline \multirow{2}{*}{ Área de Atuação } & Masculino & 4 & 22,00 \\
& Assistente Social & 2 & 11,00 \\
\cline { 2 - 4 } & Enfermagem & 7 & 39,00 \\
\cline { 2 - 4 } & Medicina & 5 & 28,00 \\
\hline & Nutrição & 2 & 11,00 \\
\hline Vínculo da & Esicologia & 2 & 11,00 \\
\hline \multirow{2}{*}{ atividade laboral } & Interno & 9 & 50,00 \\
& & 2 & 11,00 \\
\hline
\end{tabular}




\begin{tabular}{|c|c|c|c|}
\hline \multirow{5}{*}{$\begin{array}{l}\text { Possui pós- } \\
\text { graduação }\end{array}$} & Residente & 6 & 33,00 \\
\hline & Professor & 1 & 6,00 \\
\hline & Sim & 7 & 39,00 \\
\hline & Não & 4 & 22,00 \\
\hline & Em andamento & 7 & 39,00 \\
\hline Realizou curso & Sim & 8 & 44,00 \\
\hline $\begin{array}{l}\text { de capacitação } \\
\text { pelo hospital }\end{array}$ & Não & 10 & 56,00 \\
\hline Carga horária & 20 horas & 1 & 6,00 \\
\hline semanal de & 30 horas & 2 & 11,00 \\
\hline trabalho & 36 horas & 7 & 39,00 \\
\hline hospital & 40 horas & 8 & 44,00 \\
\hline Atua em outra & Sim & 4 & 22,00 \\
\hline $\begin{array}{l}\text { instituição além } \\
\text { do hospital }\end{array}$ & Não & 14 & 78,00 \\
\hline
\end{tabular}

Fonte: Direta/Entrevistas HUJM

A primeira observação realizada foi a da constatação de que as profissões relacionadas à saúde expressam um processo de feminização do setor, pois, segundo Machado; Oliveira e Moyses (2010), a inserção da mulher no setor da saúde é crescente e representa $70 \%$ da força de trabalho feminina, no entanto, nem todas as profissões da saúde detinham um número considerável de mulheres. $\mathrm{A}$ medicina, por exemplo, até pouco tempo, era uma profissão de maioria masculina, devido à regularização tardia do direito das mulheres em exercê-la, porém, atualmente, esse quadro tem se modificado. Fonte: Direta/Entrevistas HUJM

Quanto às áreas de atuação dos participantes, os grupos são classificados em: chefe de enfermagem; técnico em enfermagem; nutrição; psicologia; medicina e serviço social, sendo que todos esses profissionais têm contato direto com os cuidadores informais dos pacientes. Já sobre o vínculo laboral, nove profissionais são efetivos, seis residentes, dois internos e um professor. Dentre os participantes, 
sete realizaram pós-graduação, quatro não fizeram nenhum curso de extensão e sete estão fazendo. Dentre os que realizaram, cinco concluíram duas pósgraduações cada, sendo que a maioria desses cursos teve como tema a área de gestão ou administração hospitalar.

Sobre os cursos de capacitação oferecidos e realizados dentro do HUJM, oito profissionais participaram e dez nunca realizaram. Aqueles que já participaram citaram que o hospital sempre oferece esse tipo de atividade de aprimoramento, dentre os cursos citados: Gestão de qualidade; Cuidados com os pacientes; Carrinho de emergências; Uso de materiais e equipamentos; Medicação e Cuidados de enfermagem; Urgência e Emergência; Preceptoria; Atendimento a vítimas de violência doméstica e Reanimação cardiopulmonar.

A maioria trabalha 40 horas semanais, seguida dos que trabalham 36,30 e 20 horas, respectivamente. Dentre os entrevistados, quatro profissionais trabalham em outras instituições e 14 somente no HUJM.

\subsubsection{CATEGORIZAÇÃO E ANÁLISE DOS DADOS TEÓRICOS}

Para a realização da organização dos dados para análise, foi considerado o modelo abordado por Minayo (2013), conhecido por categorias analíticas. Esse tipo de investigação é realizado com base em eixos teóricos que norteiam a análise a partir da mediação da parcela contextual dos conteúdos, na busca por revelar as concepções abstratas contidas no discurso dos entrevistados. Diante dos dados recebidos, a pesquisadora confrontou as teorias e pressuposições sobre o tema e a realidade encontradas na fase exploratória, colocando em dúvida as ideias préconcebidas, na busca da construção da realidade mais próxima possível do objeto de estudo.

Já em um segundo momento, foi realizada uma nova leitura, dessa vez, respeitando os subconjuntos de classificação realizados na etapa anterior. É aqui que foram realizadas as divisões das entrevistas em 'unidades de sentido' ou 'tópicos de informação', que possibilitaram a construção de núcleos de sentido agrupados por 
semelhança e que formaram as categorias por meio de suas conexões subjetivas. A última etapa foi a análise final, com o movimento circular que se mobiliza por meio do empírico e o teórico, buscando riquezas entre os particulares e o geral (MINAYO, 2013).

Para essa fase, foi utilizada a técnica da hermenêutica dialética. Segundo Minayo (2010), a abordagem hermenêutica é desenvolvida na busca das diferenças e semelhanças entre o contexto dos autores e do investigador. Sendo assim, a junção da hermenêutica e da dialética se traduz em uma importante ferramenta na articulação das pesquisas qualitativas, já que ambas possuem o intuito da busca pela aproximação da verdade do objeto de estudo, enquanto se complementam também nas diferenças, pois, na medida em que a primeira valoriza a mediação, a segunda dá valor à crítica.

Seguindo essa metodologia, foi possível compilar os relatos dos participantes segundo as variações de estudo, quais sejam: 1 - A opinião do profissional de saúde: qual é o conceito de saúde e a importância do cuidador; 2 - Conhecimento dos profissionais de saúde a respeito das práticas que envolvem a rotina do cuidador informal e 3 - Relacionamento entre cuidadores e profissionais de saúde na prática.

\subsection{ANÁLISE E RESULTADOS}

\subsubsection{A OPINIÃO DO PROFISSIONAL DE SAÚDE: QUAL O CONCEITO DE SAÚDE E A IMPORTÂNCIA DO CUIDADOR}

A Organização Mundial de Saúde (OMS) traz a definição de saúde não apenas como a ausência de doença, mas como a situação de perfeito bem-estar físico, mental e social. Para Assumpção, Morais e Foutoura (2002), a saúde, antes reduzida à função biológica de causa e efeito, hoje deve ultrapassar essa concepção e primar para o estado físico e mental de bem-estar e prazer. 
Nesse sentido, os profissionais de saúde participantes possuem opiniões consonantes, demonstrando que consideram a subjetividade dos pacientes como parte integrante da condição de se manter saudável, como é possível averiguar em algumas falas:

Saúde é um conceito estado de bem-estar, porém esse bem-estar envolve condições, físicas, psicológicas, psicobiológicas, sociais... é um conceito mais amplo de saúde de você estar bem, em relação a sua condição orgânica e em relação a sua condição social e psicológica. ( $2^{\circ}$ entrevistado)

Eu entendo como saúde um conjunto de fatores né, que combinam com é....bem-estar do indivíduo não só falta de não ter doença mais com qualidade de vida. (11ำ entrevistado)

Kovács (2008) afirma que a situação da hospitalização de um ente querido provoca profundas alterações na vida familiar, tanto no sentido de afastamento do doente do convívio no lar e das pessoas ao seu redor como das suas atividades rotineiras, por exemplo, no trânsito dos familiares para o hospital, resultando em isolamento, quebra de relações sociais, familiares e de trabalho, surgindo, nesse momento, a figura que deve ser o foco de atenção: o cuidador, aquele membro da família que fica responsável pelos cuidados, que acompanha o paciente na internação e que auxilia no tratamento, sendo imprescindível para a promoção, prevenção de doenças ou adaptação do paciente nessa fase.

Dentro desse contexto, foi perguntado sobre a importância da presença do acompanhante/cuidador familiar no processo de recuperação do paciente internado, sendo que o fator emocional foi aquele que mais apareceu dentre as justificativas dos entrevistados na ênfase da relevância do cuidador. Isso vai ao encontro dos estudos de Gurley (1995), que afirma que os membros da família oferecem suporte emocional e conforto ao enfermo, o que torna ainda mais relevante a função do cuidador, o que foi corroborado pelos relatos dos profissionais de saúde.

Pra mim é muito importante viu, porque tem paciente que fica aí sozinho a gente às vezes acha que recuperação dele é um pouco mais demorada assim, ter uma pessoa do lado. É muito chato você não ter ninguém pra conversar, você fica quanto tempo aqui internado, né! Tem paciente que fica dois três dias, semanas, meses então fica sozinhos (pausa), essa relação tem 
um pouco haver em o acompanhante estar do lado do paciente. (4은 Entrevistado)

Ah, eu acho que muita, pois quando o paciente não sente a presença de um parente, de algum responsável por ele, o emocional dele fica muito abalado e o acompanhante ajuda muito, é visível, né! Tem casos que não, mas a maioria dos casos sim. (5ํㅡㄹ Entrevistado)

Tarefas ligadas aos cuidados básicos, à alimentação, à higiene e à mobilidade também foram destacadas como realizadas por muitos cuidadores, no entanto, nem todos estão preparados para esse tipo de função. $O$ fato de o cuidador ter de aprender e assimilar certos cuidados com o paciente, no contato com os profissionais de saúde, também foi ressaltado como de grande importância, especificamente em casos em que esses cuidados serão também estendidos para o ambiente domiciliar. Dessa forma, é importante que eles acompanhem a rotina de cuidados, tornando a mudança de um ambiente hospitalar para familiar menos traumática.

\subsubsection{CONHECIMENTO DOS PROFISSIONAIS DE SAÚDE A RESPEITO DAS PRÁTICAS QUE ENVOLVEM A ROTINA DO CUIDADOR INFORMAL}

Medeiros; Gonçalves e Oliveira (2003) reiteram que é primordial que as unidades de saúde e o Estado ofereçam condições de infraestrutura e de suporte para que os familiares possam efetivamente exercer o papel de cuidadores informais. Os autores frisam que se torna necessário conhecer as necessidades de cuidado da pessoa dependente, assim como a situação de suas famílias: demandas, crenças, valores e práticas socioculturais.

Dessa forma, as questões de análise que se buscaram levantar foi se eles conhecem as práticas que envolvem a rotina do cuidador; quais são os critérios estabelecidos pelo HUJM para que o acompanhante seja considerado um cuidador; quais são as rotinas dos acompanhantes cuidadores na clínica; quais são os direitos oferecidos a esses cuidadores; como é a postura dos cuidadores diante de seus direitos e se existe algum tipo de atendimento aos cuidadores no hospital. 
Acerca dos critérios para ser considerado acompanhante na unidade, se são conhecidos ou não pelos profissionais de saúde entrevistados, a maioria respondeu desconhecer os detalhes sobre esse assunto. Porém, citaram o que acreditam ser regra geral dos hospitais brasileiros: são permitidos acompanhantes aos menores de 18 anos, maiores de 60 anos e àqueles que possuem alguma limitação física ou mental ou, de acordo com o estabelecido pela Legislação Brasileira, por meio do Estatuto da Criança e do Adolescente, do Estatuto do idoso, assim como da Portaria 1820, de 2009, do Ministério da Saúde, que dispõe sobre os direitos e deveres do usuário da saúde. A Lei n. 106/2009 trata sobre os critérios de acompanhamento familiar em internamento hospitalar, dessa forma, o profissional da saúde menciona que:

Sim, os critérios de acompanhante são menores de dezoito anos, maior de 60 anos, e em alguns casos é avaliado também o quadro do paciente. Pacientes portadores de necessidades especiais têm direito a acompanhantes, pacientes que são acamadas independentemente da idade também tem direito a acompanhante, e depende muita da clínica também do paciente, se o paciente ele tiver alguma patologia e necessita de um cuidado maior ele vai ter o direito a acompanhante. (2ำ Entrevistado)

No entanto, três pesquisados alegaram que esses critérios não existem e mesmo aqueles que os conhecem parcialmente disseram que acabam colocando em prática aquilo que considera razoável, conforme cada caso.

Não, porque aqui não tem critério a pessoa interna e são os parentes que vem ou conhecidos, não tem critério que eu saiba. (4ํㅡㄹ Entrevistado)

Exatamente aqui no hospital Júlio Muller, eu vou dizer pra você que eu não conheço, mas assim, em visão de outros hospitais, eu acredito que seja: não ser menor de idade e estar, eu acho que numa condição física pelo menos né o suficiente pra você auxiliar nesse cuidado com esse acompanhante e o critério médico mesmo, né, em a pessoa precisar de um acompanhante. ( $7^{\circ}$ Entrevistado)

Sobre a rotina dos cuidadores informais na clínica ser percebida pelos profissionais de saúde, apesar de os entrevistados não conhecerem detalhes dessas rotinas, a maioria citou que, de modo geral, os cuidadores auxiliam em tarefas necessárias para a manutenção do bem-estar do paciente, como banhos ou administração das refeições. 
[...] o acompanhante ele participa de atividades do dia a dia né, auxilia em cuidado como banho aqui, mas, é mais no banho mesmo que eles auxiliam a questão da dieta também os acompanhantes auxiliam porque tem muito paciente que tem dificuldade de se alimentar, então o acompanhante que dá essa dieta, é que tem paciente que não consegue comer mesmo e o acompanhante que tem que pegar e dar boca tudo certinho, então é isso que eles fazem. ( $2^{\circ}$ Entrevistado)

O acompanhante que fica todo tempo acompanhando. Eu não sei se tem alguma rotina estabelecida, eu sei que ele fica cuidando do paciente e que tem direito a essas refeições e tal, mas eu não sei se tem assim, alguma coisa determinada pra ele de rotina não. (13ํㅡㄹ Entrevistado)

Leal (2000) afirma que o cuidador informal se expõe a uma série de fatores estressantes, que incluem o peso das tarefas diárias e as consequentes doenças advindas das exigências do trabalho. Dessa maneira, a deterioração do estado de saúde e de nutrição do cuidador colocam-no em risco de desenvolver doenças, diminuindo a sua capacidade de prestar cuidados, o que piora não só sua qualidade de vida, mas também a do receptor (SILVER; WELLMAN, 2002).

Perguntados sobre os direitos dos cuidadores, um dos profissionais de saúde reiterou que os cuidadores possuem o direito de conhecer e acompanhar a história clínica do paciente, porém a maioria dos pesquisados respondeu que desconhece os direitos e quatro deles ainda se negaram a responder, sugerindo também desconhecerem.

Olha! Eu acredito que ele deve ter muitos, mas eu não tenho conhecimento de todos eles. Eu acredito que a gente na prática execute alguns, acho que outros deixam a desejar e muito (pausa), mas eu não conheço para dizer legislativamente o que ele tem direito, isso eu não sei. (5ํㅡㄹ Entrevistado).

Especificamente falando em uma normativa aqui no Júlio Muller não tenho o conhecimento de nenhum direito dele. (7ํㅡㄹ Entrevistado)

Percebeu-se que os entrevistados, em sua maioria, não sabem concretamente quais são os direitos dos acompanhantes e cuidadores, mas se guiam pelo que acreditam serem nessa perspectiva. Alguns até citaram as rupturas desses direitos, principalmente no concernente à refeição, à falta de estrutura no hospital e às melhores condições de estadia ou alimentação. 
A maioria deles desconhece, né. É bem comum eles chegarem aqui e acreditar que todos eles têm direito a refeição né, no caso, a gente sabe que todos eles têm direito de permanecer aqui, qualquer um que está internado tem direito a um acompanhante, mas dentro dos critérios a gente avalia a questão da liberação do almoço ou não. (8ํㅡㄹ Entrevistado)

Vale destacar que a opinião dos profissionais do Serviço Social do hospital é de que todo e qualquer acompanhante possui o direito de receber as refeições. Segundo a portaria n.ำ 280/99 do Ministério da saúde, os hospitais públicos contratados ou conveniados com o Sistema Único de Saúde - SUS — devem viabilizar os meios para permitir a presença do acompanhante de pacientes maiores de 60 anos. Alguns profissionais acreditam que esse direito é estendido aos cuidadores, a partir do direito humano à alimentação assegurado como prerrogativa garantida.

Karsch (2003) destaca que, além da assistência às pessoas doentes/hospitalizadas, o suporte aos cuidadores informais (leigos) representa um novo desafio para o Sistema de Saúde brasileiro. Isso corrobora com os estudos de Briceño-León R. et. al. (2000) de que as instituições de saúde, na maioria das vezes, não estão estruturadas para os atenderem, sendo que o descaso e a falta de planejamento da instituição podem refletir nos cuidados prestados ao doente.

O que eu acho pior de tudo na clínica médica, os acompanhantes é que não tem onde eles repousarem né, nem onde dormir eles trazem um colchãozinho de casa, eles trazem cadeira de casa. Não sei como isso poderia ser resolvido já que a maioria não comportaria camas pra acompanhante. $E$ isso provoca um desgaste com certeza muito grande porque a gente tem muitos pacientes crônicos que ficam meses aqui com o acompanhante. $E$ às vezes a família só tem uma pessoa que possa acompanhar então essa pessoa fica meses dormindo numa cadeira [...]. (19² Entrevistado)

Sobre as questões referentes ao suporte dado pelo hospital à saúde dos cuidadores: "Existe algum tipo de atendimento?" "O que ocorre quando o cuidador adoece?", o consenso foi que não existe atendimento médico ao cuidador que se enferma durante suas atividades, ocorrendo somente em casos de extrema urgência, como doenças crônicas, em que ele é examinado e orientado para que procure um posto de saúde, pois o hospital não possui pronto atendimento. Nesses casos, o acompanhante é substituído por outro familiar e, quando não há quem o substitua, o paciente permanece sem esse auxílio. 
Então quando o acompanhante adoece a gente solicita que venha outro acompanhante para acompanhar. [...], quando ele fica doente a gente solicita que venha um novo acompanhante né pra ficar cuidando desse paciente, mas aí a gente sabe que varia de família para família, tem família que tem essa disponibilidade de mandar outro acompanhante, mas tem família que não e só tem aquela pessoa e às vezes aquela pessoa acaba ficando doente mesmo [...]. ( (2o entrevistado)

Carvalho Filho (2005) aponta que diversos desafios estão presentes no cotidiano do cuidador, tais como a dificuldade para lidar com os quadros de agitação e de agressividade do ser cuidado, com a deambulação constante, especialmente noturna, provocada pelas alterações nos hábitos de sono e repouso, com os esquecimentos, a repetitividade, a teimosia e as solicitações constantes etc.

Em nível emocional e psicológico, a sobrecarga dessas atividades pode manifestarse por irritabilidade, insônia, alteração de humor, isolamento social e aumento da ingestão de álcool ou outras drogas pelo cuidador, que experimenta um aumento de estresse e de ansiedade, gerando consequências graves na saúde física e emocional (VERÍSSIMO; MOREIRA, 2004).

O que se pode perceber nos apontamentos dos profissionais entrevistados é que, muitas vezes, a doença do cuidador é decorrente do desgaste do cuidado diário do paciente que ele acompanha, como é possível verificar na fala a seguir:

Então, esse é um fator (pausa) é uma implicação de doença do paciente, às vezes acarreta no cuidador né, às vezes a gente se depara com o cuidador tão sobrecarregado, tão cansado, tão estressado que ele acaba adoecendo junto com o paciente né. E quando é um caso de muito tempo de internação em que o paciente fica aqui por um bom período e só tem aquele cuidador, só aquela pessoa disponível para cuidar dele a gente vê uma doença psíquica nesse cuidador, e aí a gente no caso da minha profissão oferecemos o serviço tanto para a família quanto para o paciente, então a gente acaba acompanhando o familiar e o paciente ao mesmo tempo [...]. (14은 Entrevistado)

Para além dos males físicos, doentes com problemas de saúde mental têm reflexos diretos na saúde mental dos cuidadores (FRIAS; TUOKKO; ROSENBERG, 2005). Assim, o cuidador também está propenso a desenvolver alguma doença psíquica, por isso existe também suporte psicológico e acolhimento do assistente social, o que 
foi citado pelos pesquisados ao serem questionados sobre 0 atendimento aos cuidadores, conforme se verifica na fala que segue.

Quando o acompanhante adoece nós comunicamos à medicina, que é feito uma avaliação com o acompanhante no caso de saúde, como posso dizer: físico. Mas se a gente percebe uma demanda psicológica, psicossocial, a gente faz essa ponte com a equipe da psicologia e também com a equipe do serviço social. Já aconteceram casos em que houve problemas familiares, aí essa pessoa se abalou psicologicamente e não soube lidar com o que estava acontecendo lá fora e o que estava acontecendo aqui dentro, aí nesses casos a gente busca esse tipo de apoio, porque eu entendo que a adoecer aqui não é somente o adoecer físico, mas o psicológico é o que mais acontece. (1ํㅡㄴ Entrevistado)

\subsubsection{RELACIONAMENTO ENTRE CUIDADORES E PROFISSIONAIS DE SAÚDE NA PRÁTICA}

Em relação à visita aberta e ao direito ao acompanhante, disponibilizados pelo Ministério da Saúde, na cartilha da PNH, o acompanhante é apontado como elemento de obstrução ao trabalho profissional, um volume a mais, uma demanda que precisa ser controlada, assim, ocorre a necessidade de profissionais destinados a esse tipo de acolhimento. Na dinâmica do cuidado, os serviços de saúde, diante da hierarquização das ações, individualizam o trabalho nos serviços e não empoderam o usuário para que possa alterar as condições de vida e saúde (VASCONCELOS, 2002).

Dessa maneira, algumas perguntas das entrevistas foram direcionadas a avaliar o relacionamento entre cuidadores informais e profissionais de saúde do HUJM, visto que as dificuldades presentes no relacionamento interpessoal entre essas figuras dificultam e interferem negativamente nas rotinas de ambos. Assim, buscou-se saber a compreensão dos entrevistados sobre a postura do cuidador no período das visitas dos profissionais no leito, se o cuidador acessa os serviços disponibilizados pelo hospital, se o acompanhante ou cuidador é levado em consideração no tratamento do paciente e se as políticas de saúde promovem a humanização do cuidado ao acompanhante/cuidador de forma integral. 
Sobre o fato dos cuidadores ou acompanhantes servirem, muitas vezes, como facilitadores para a adaptação do paciente ao ambiente hospitalar, foi citado:

Ele fica receoso, às vezes ele tem dúvidas e não tende a perguntar, mas assim, na medida do possível a gente tenta explicar tudo para o paciente e para o acompanhante da maneira mais simples que ele possa entender também. É muito importante que ele esteja a par do que está sendo feito aqui no hospital né, tem muito paciente que desiste do tratamento e vai embora porque não sabe o que está se passando. (10ํㅡㄹtrevistado)

O comportamento do cuidador tende a estar ligado a questões pessoais de aceitação de seu papel, o que corrobora a opinião de que, na aquisição da atividade de cuidador, pode ser que o indivíduo manifeste dificuldades na execução, percepção e adequação à sua nova função, o que, muitas vezes, resulta em incerteza, despreparo, pouco conhecimento e necessidade de mais informação, recursos materiais e humanos, bem como do auxílio de profissionais da área da saúde, o que pode justificar esse comportamento mais retraído ao receber as informações que Ihes são passadas (IMAGINÁRIO, 2004).

\begin{abstract}
Depende do acompanhante né, tem acompanhante que fica lá no canto dele. E geralmente a gente tem uma rotina na clínica médica e os residentes passam nos pacientes e conversam né, e aí é mais nesse momento, geralmente mais os residentes que acabam conversando com os acompanhantes e explicando tanto pro paciente tanto pro acompanhante a situação do paciente. Ah! O que ele vai fazer no dia, se ele vai fazer algum exame ou quantos dias de antibiótico que falta, tudo depende muito do perfil do acompanhante é que, tem gente tão humilde que só fala assim "Ah uhum" tem outros que não, já te contesta o tempo inteiro: "ah, mas porque isso? Por que aquilo? Por que essa injeção? Ah, mas não sei o que, cadê o exame que o doutor falou?". Então é isso a postura deles em relação à gente né, e em relação ao médico. (19ํㅡㄹ Entrevistado)
\end{abstract}

Sobre as dificuldades encontradas em relação ao cuidador, os profissionais de saúde voltaram a citar as condições precárias do ambiente para acolhê-los, o que gera estresse e tensão entre as partes. A respeito do questionamento sobre a existência de acesso dos acompanhantes aos serviços do hospital, as dificuldades na estadia, alimentação e banho dos acompanhantes, todos os entrevistados reiteram a falta de estrutura física como o maior entrave ao exercício desses direitos, o que está de acordo com a PNH do Ministério da Saúde, sobre a precariedade das instituições em acolher os acompanhantes (BRASIL, 2007). 
[...] Nossa maior dificuldade é que o ambiente não possui preparo físico para acolher em uma enfermaria com cinco pacientes e cinco acompanhantes, né. Nós temos pacientes e na maioria deles são do interior, quando eles veem eles trazem bastante bagagens, malas e ficam naquele quarto apertado. Isso dentro da vigilância sanitária e das normas RDC, elas não são respeitadas quando acontece isso. Então eu sinto dificuldades, o hospital ele não tem o espaço intermediário onde a gente possa levar esses materiais e muita das vezes os municípios não fornecem casa de apoio então fica uma situação difícil para acomodar esse acompanhante. Acredito que uma cadeira de fio não é o suficiente para dar conforto para o acompanhante, se ele fica trinta, quarenta dias aqui começa a desenvolver um problema físico por estar sentado numa cadeira por muito tempo e dormir naquela cadeira. Então nesse sentido que eu acho que é a nossa maior dificuldade com o acompanhante [...]. ( $1^{\circ}$ entrevistado)

Um dos fatores que foi evidenciado como responsável pelo aumento do nível de estresse entre cuidadores e os profissionais de saúde foi a interferência dos cuidadores informais na rotina de pacientes que não estão acompanhando. Ocorre que as enfermarias abrigam vários pacientes e, ao tentar auxiliar algum internado que não é aquele que está acompanhando, os cuidadores acabam por atrapalhar a rotina de atividades dos profissionais de saúde, uma vez que desconhecem as necessidades específicas daquele paciente.

[...] A gente faz dentro de enfermaria mesmo e às vezes a gente tem aquele acompanhante que quer ajudar a todos os outros pacientes, mas o paciente, a pessoa que ele está acompanhando é uma pessoa que está em precauções de contato. Ele é orientado de como proceder com esse paciente, mas aí ele quer ajudar o outro paciente e aí acaba que forra a cama do paciente do lado, a gente pede pra não fazer porque a equipe de enfermagem já faz isso, mas quando você vira as costas ele já foi lá e forrou a cama, já pegou no paciente sem luvas, já ajudou a levar no banheiro, então ele não chama a equipe, então a gente tem essas dificuldades. ( $2^{\circ}$ Entrevistado)

A comunicação também se mostrou ineficiente, pois é possível extrair das entrevistas que os profissionais participantes ou não gostam, ou percebem que seus colegas de trabalho não gostam de serem questionados pelos pacientes sobre suas atividades rotineiras. Isso acontece, em parte, pelo fato de ainda verem os cuidadores como pessoas que estão em desordem ou que comprometem o seu trabalho e não como alguém que esteja ali para auxiliar ou, ainda, pela sobrecarga dos profissionais, que não se veem com tempo viável para tirar as dúvidas dos 
cuidadores e pacientes de maneira satisfatória, o que interfere negativamente na construção dos relacionamentos (BRASIL, 2007).

E essa questão também da comunicação eu acho que tem que envolver o acompanhante no processo de cuidado o tempo todo e também olhar para ele né, não adianta só a gente cuidar do paciente sem considerar o familiar cuidador, seja quem for. Eu acho que é o maior empecilho. (14ํㅡㄹ Entrevistado)

Depende de como ele se porta, mas assim às vezes tem sim, principalmente com o pessoal da enfermagem que está mais direto lá na clínica. Eu já ouvi relatos e presenciei um pouco de resistência, às vezes o acompanhante tumultua um pouco, né? Às vezes, o acompanhante cobra demais. Então assim, pra equipe eu acho que se torna incômodo nesse sentido de achar que o acompanhante cobra demais, fica em cima demais, tumultua os serviços, mas acho que a dificuldade seria mais nesse sentido [...]. (15을 Entrevistado)

No entanto, mesmo com as observações sobre as dificuldades na comunicação, os profissionais de saúde avaliam os seus relacionamentos com os pacientes e cuidadores como satisfatórios:

A minha relação eu acredito que é boa, por isso eu falo do olhar que se tem e a importância que têm ele ali. Então eu respeito o paciente internado, quanto o acompanhante e quando eu estou falando diretamente com o paciente e se o acompanhante interrompe e vem trazer uma alguma coisa, eu escuto atentamente porque eu acho que tudo que eles vêm trazer é importante é... eu acredito que a relação é cordial e da melhor forma possível. (7ํㅜㄴ Entrevistado).

Sobre o cuidador ser levado em consideração no tratamento do paciente, de acordo com Sanches et al. (2013), o acompanhante passou a ser reconhecido como facilitador do restabelecimento da saúde do paciente e catalisador do processo de reabilitação, sendo capaz de manter vínculos afetivo e social e assegurar o suporte emocional, devido à valorização da importância de se ter alguém no processo da dinâmica do cuidado.

Além de avaliar essa relação positivamente, os profissionais reiteraram a importância desse bom relacionamento com o acompanhante na extração de informações sobre o paciente, o que auxilia no seu acompanhamento.

A gente sempre conversa com o paciente e com o acompanhante. $O$ acompanhante também e fonte importante de informações durante a internação principalmente, inclusive alguns pacientes chegam a um estado

RC: 105240

Disponível em: https://www.nucleodoconhecimento.com.br/saude/cuidador-informal 
confusional então quem vai mais dar informação para gente é o acompanhante e durante a evolução também, porque o acompanhante está com o paciente até mesmo antes da internação, então ele é fonte importante de dados pra gente vê o decorrer da evolução do paciente e na hora da internação também. (10ํㅡㄹ Entrevistado)

Sobre a questão do acolhimento ao cuidador, o que pode se depreender é que não existe um serviço que o inclua desde a sua chegada, no intuito de auxiliar psicológica, física ou assistencialmente a construção do atendimento acolhedor, baseado em atitude de inclusão e vínculos que permitam dar passagem aos interesses, necessidades e desejos dos sujeitos dessa relação, ou seja, eles não são considerados como parte do atendimento ao paciente, existindo apenas o auxílio para aqueles cuidadores que já apresentam dificuldades ao longo de seu acompanhamento, sendo evidente a ausência de serviços preventivos de problemas psicológicos ou físicos que possam surgir, ocorrendo somente a reparação daqueles que já surgiram.

Essa estratégia vai ao encontro do que é considerado ideal por Briceño-León (2000), o qual destaca que deve haver a integração dos múltiplos aspectos que integram o processo saúde-doença, tanto do paciente quanto do cuidador, na qual se considera a prevenção e a promoção juntamente com a atenção curativa.

A prioridade é para o paciente e aí se o profissional observa a necessidade desse acompanhante ser atendido aí é essa maneira que ele começa a perceber, quando há conflito ou quando o acompanhante ele vai para casa e começa a trazer muito problema para esse paciente. Então também há intervenção desse estresse que ele causa a esse familiar, esse familiar pode entrar em choque com a equipe médica muitas vezes o familiar ele interfere ali na rotina então ele fica cuidando se o profissional está agindo corretamente "para que é esse remédio? Então ele começa a interferir muito e as vezes ele entra em conflito com a equipe então nesses casos também tem intervenção com relação ao familiar. (16ํㅡㄹ Entrevistado)

Questionados sobre se as políticas de saúde promovem atendimento humanizado ao acompanhante de forma integral, a maioria dos entrevistados respondeu que não, já que os serviços e apoio promovidos servem apenas, em parte, ao suprimento das necessidades dos acompanhantes. Dessa maneira, muitos citaram que, na prática, essas políticas se distanciam muito do ideal estabelecido pelos órgãos e entidades de saúde. Tais falas discutem, principalmente, sobre a falta de investimento na 
estrutura física, no desenvolvimento e no provimento de pessoal capacitado, assim como na disponibilidade de programa de gestão que receba o acompanhante como parte integrante do atendimento ao paciente.

Em parte, sim. Em parte, porque é no hospital que tudo é feito para o paciente né, então muitas vezes quando é necessário que o acompanhante, precise ficar então ele tem certa adaptação a isso, tipo arruma uma cadeira, mas não tem aquele apoio que deveria ter para o acompanhante. Dependendo da clínica, por exemplo, aqui no hospital a pediatria tem um apoio maior para as mães, porque são crianças então é comum que as crianças fiquem acompanhadas dos pais ou responsáveis, então lá, eles têm uma estrutura melhor para receber esse acompanhante. Já nas outras clínicas nem tanto. (3ํㅡㄹ Entrevistado)

O não atendimento aos requisitos gerais que elevem o atendimento ao paciente e ao acompanhante aos parâmetros de humanização é considerado como uma falha na eficácia de práticas de atenção integral nos serviços. Martins (2006) destaca que abarcar as necessidades, tanto do paciente quanto do acompanhante, é fundamental para o fortalecimento dos projetos de humanização das instituições de saúde, tão em evidência nos dias de hoje. A autora ainda alerta que, ao negligenciarmos algum aspecto, a humanização acaba por falhar ao cuidar somente da parte estrutural dos prédios ou do conjunto de relações presentes no cotidiano dos serviços, sem agregar ambos os cuidados.

\section{CONSIDERAÇÕES FINAIS}

A internação ou hospitalização de um ente querido costuma provocar alterações na vida familiar, tanto na rotina do paciente quanto daqueles que fazem parte de sua vida. Nesse cenário de adaptação e turbulência, estabelecem-se papéis que vão reconfigurar as atividades de cuidado, em que, geralmente, um dos familiares (em sua maioria, do gênero feminino) fica responsável pelo acompanhamento e suporte ao doente nas tarefas rotineiras. Essa reconfiguração da rotina, na maioria das vezes, resulta em sobrecarga de trabalho e pode despertar diversos sentimentos ambivalentes no cuidador, podendo também resultar em problemas físicos e psicológicos. 
Tendo em vista os aspectos observados, as particularidades do acompanhantecuidador também devem ser levadas em consideração, pois ele se orienta por meio de sua história de vida, seus valores, religião, trabalho, possibilidades, desejos, dificuldades, entre outros. Os trabalhadores da saúde devem realizar esse recorte para que ocorra tal aproximação, pois são essas características que ditam a forma como o relacionamento paciente $\mathrm{x}$ profissional $\mathrm{x}$ cuidador de saúde vai se desenvolver.

Para cuidar, é necessário que os cuidadores sejam munidos de informação, educação, incentivo e segurança para a boa execução de suas tarefas, visando humanizar o atendimento. Dessa forma, o papel dos profissionais de saúde é fundamental para responderem a essas necessidades, pois, ao acolher os cuidadores, eles propiciam adaptação e capacidade de lidar com as situações que Ihe serão impostas pela situação de adoecimento, considerando também atender às necessidades dos usuários dos serviços.

As peculiaridades do trabalho em saúde também entram em cena, assim como a variabilidade das situações cotidianas, a mutabilidade do trabalho e das atividades e o grau de produção do cuidado na ótica do saber técnico-científico, os quais refletem na relação intersubjetiva dos cuidadores - trabalhadores - assim como na multiplicidade de característica individual, que interfere na construção de mudanças no serviço de saúde, distanciando das práticas de atenção à saúde.

Portanto, o cuidador tem um importante papel de ligação entre a equipe de saúde e a pessoa cuidada, executando tarefas necessárias, entretanto, mais que isso, da mesma maneira que o doente, o cuidador é usuário do serviço de saúde e também requer atenção específica, definindo-o como parte integrante, inclusive no cuidado, sem contar as dificuldades dentro do próprio hospital, que foi bastante descrita neste estudo, mantendo o acesso a bens e serviço de saúde de acordo as necessidades de infraestrutura e as diversas situações clínicas.

Dessa forma, as intervenções da equipe de saúde devem utilizar a estratégia para além da doença, contribuindo, consequentemente, para que o período de internação 
e a posterior volta ao domicílio sejam realizados de forma mais amena possível, fortalecendo os laços entre paciente e cuidador, enxergando, neste último, um aliado para o reestabelecimento do paciente, por meio da humanização do atendimento com atitudes que respeitem a integralidade do sujeito, a materialização do cuidado integral entre os diferentes saberes, bem como as necessidades diversas.

A demanda dos cuidados com cuidadores deve também ser priorizada pela gestão, justamente pela complexidade que a define, para o alcance da eficiência no oferecimento do cuidado. É importante que se amplie a troca de saberes, com práticas que favoreça a cooperação das relações dentro das unidades de saúde, entendendo e problematizando as lógicas dos processos de gestão, analisando os resultados daquilo que está sendo realizado, no intento de produzir novos sentidos, ampliando o que a gestão possui de positivo e descartando os pontos considerados negativos.

Há que reconhecer que não existe cadeia de cuidados sem a articulação da unidade de saúde hospitalar com outros setores e pessoas responsáveis pela ampliação e diversificação dessa oferta. É imprescindível manter a compreensão do cuidado interdisciplinar, para continuidade do cuidado diferenciado, usufruto de boas práticas em saúde, assim como o atendimento humanizado, preventivo, que consiste na execução, formulação e execução de políticas de saúde que vise à redução dos riscos de doenças e outros agravos no paciente. Isso vai desde as diferenças nas condições de vida e saúde bem como a atividade terapêutica não reduzida à dimensão biológica, psicológica e social.

Especificamente no HUJM, para que isso ocorra, alguns aspectos devem ser priorizados, tanto do ponto de vista do investimento na estrutura física quanto na melhoria da comunicação entre pacientes e cuidadores $x$ profissionais de saúde.

Este estudo não tem a pretensão de exaurir os temas que englobam a questão do cuidado aos cuidadores e nem de apresentar soluções concretas para as lacunas na qualificação do cuidado que possam ter surgido no atendimento do referido hospital, e sim objetiva contribuir para a melhoria dos aspectos aqui levantados por meio da 
pesquisa, servindo como apoio a outros estudos que buscarão o aperfeiçoamento no atendimento hospitalar.

\section{REFERÊNCIAS}

ASSUMPÇÃO, Luís Otávio Teles; MORAIS, Pedro Paulo de; FONTOURO, Humberto. Relação entre atividade física, saúde e qualidade de vida: Notas introdutórias. EFD esportes. Revista Digital. Ano 8. n. 52. Buenos Aires (Argentina), 2002.

BRASIL. Ministério da Saúde. Secretaria de Atenção à Saúde. Secretaria de Gestão do Trabalho e da Educação na Saúde. Guia Prático do Cuidador. Brasília-DF: Ministério da Saúde, 2008. Disponível em: http://bvsms.saude.gov.br/bvs/publicacoes/guia_pratico_ cuidador.pdf. Acesso em: 18 de fev. 2020.

BRASIL. Conselho Nacional de Secretários de Saúde. Humaniza SUS: visita aberta e direito a acompanhante. 2007. Disponível em: http://bvsms.saude.gov.br/bvs/publicacoes/ visita_acompanhante_2ed.pdf. Acesso em: 06 de jan. 2020.

BRASIL. Ministério da Saúde. Secretaria de Atenção à Saúde. Cadernos Humaniza SUS; v.3. Brasília: Ministério da Saúde, 2011. Disponível em: http://redehumanizasus.net/wp- content/uploads/2017/09/Cadernos-HumanizaSUSVolume-3-Atenc\%CC\%A7a\%CC\%83o- Hospitalar-1.pdf. Acesso em: 6 jan. 2020.

BRICEÑO-LEÓN, Roberto. Bienestar, salud pública y cambio social. In: BRICEÑOLEÓN, Roberto; MINAYO, Maria Cecília de Souza; COIMBRA JUNIOR, Carlos E. A. Salud y equidad: una mirada desde las ciencias socieales. p. 15-24. Rio de Janeiro: Fiocruz, 2000.

CARVALHO FILHO, Eurico Thomaz de. Fisiologia do envelhecimento. In: PAPALÉO NETTO, Matheus; CARVALHO FILHO, Eurico Thomaz de. Geriatria: Fundamentos, clínica e terapêutica. 2. ed. p. 43-62. São Paulo: Atheneu, 2005. 
FEUERWERKER, Laura Camargo Macruz; CECÍLIO, Luiz Carlos de Oliveira. O Hospital e a Formação em Saúde: desafios atuais. In: Revista Ciência e Saúde Coletiva. v. 12, n. 4, p. 965-971. Rio de Janeiro: Jul-Ago, 2007. Disponível em: http://www.scielo.br/scielo.php? script=sci_arttext\&pid=S1413-81232007000400018. Acesso em: 10 jan. 2020.

FEUERWERKER, Laura Camargo Macruz. A Cadeia do Cuidado em Saúde. In: MARINS, João José Neves; REGO, Sérgio (orgs.). Educação, Saúde e Gestão. Rio de Janeiro e São Paulo: ABEM - Hucitec, 2011. Disponível em: http://www.ufrgs.br/cuidadocomapele/arquivos/textos_para_leitura/a_rede_de_atenc ao_a_saude_e_o_sus/a_cadeia_do_cuidado_em_saude.pdf. Acesso em: 10 jan. 2020.

FIGUEIREDO, Vanessa; DIAS, Maria Olívia; OLIVEIRA, Alexandre. Influência do Cuidador Informal na Reabilitação do Doente, no Contexto dos Cuidados Continuados. In: Revista Gestão e Desenvolvimento. p. 269-289. Portugal: 2014. Disponível em: http://z3950.crb.ucp.pt/Biblioteca/GestaoDesenv/GD22/gestaodesenvolvimento22_2 69.pdf. Acesso em: 8 mar. 2020.

FRIAS, C. M.; TUOKKO, Holly A.; ROSENBERG, T. Caregiver physical and mental health predicts reactions to caregiving. Aging \& Mental Health, v. 9, n. 4, p. 331336, 2005.

GIL, Antônio Carlos. Como elaborar projetos de pesquisa. 6. ed. São Paulo: Ed. Atlas, 2012.

GONÇALVES, Maria do Carmo dos Santos. Políticas de Humanização e o Direito a Saúde no Rio Grande do Sul. 2007. (Dissertação de Mestrado) PUC-RS. Disponível em: http://tede2.pucrs.br/tede2/bitstream/tede/4747/1/390862.pdf. Acesso em: 6 jan. 2020. 
GURLEY, M. J. Determining ICU visiting hours. Medsurg. Nurs., v. 4, n. 1, p. 40-43, 1995.

IMAGINÁRIO, Cristina M. O Idoso dependente em contexto familiar. Coimbra: Formação e Saúde Ltda. 2004.

KARSCH, Úrsula M. Idosos dependentes: famílias e cuidadores. Cad Saúde Pública, maio; v. 19 n. 3, p. 861-866, 2003.

KOVÁCS, Maria Júlia. Avaliação da qualidade de vida em pacientes oncológicos em estado avançado da doença. In: CARVALHO, Maria Margarida M. J. de. (org.). Psico-oncologia no Brasil: resgatando o viver. São Paulo: Summus, 2008. p. 159185.

LEAL, Maria das Graças Sobreira. O Desafio da longevidade e o suporte ao cuidador. Revista da Terceira Idade, São Paulo, v. 11, n. 20, p. 19-29, 2000.

MACHADO, Maria Helena; OLIVEIRA, Eliane dos Santos de; MOYSES, Neuza Maria Nogueira. Tendências do mercado de trabalho em saúde no Brasil. In: Conferência Internacional sobre Pesquisas em Recursos Humanos em Saúde. Rio de Janeiro, 2010.

MARTINS, Teresa. Acidente Vascular Cerebral: Qualidade de vida e bem-estar dos doentes e familiares cuidadores. Coimbra: Formação e Saúde Ltda., 2006.

MEDEIROS, Horácio Pires; GONÇALVES, Lúcia Hisako Takase; OLIVEIRA, Marília de Fátima Vieira. Idosos, família e cultura: um estudo sobre a construção do papel do ou cuidador. Campinas: Alínea, 2003.

MERHY, Emerson Elias. A Perda da Dimensão Cuidadora na Produção da Saúde: uma discussão do modelo assistencial e da intervenção no seu modo de trabalhar a assistência. In: O SUS em Belo Horizonte. São Paulo: Ed. Xamã, 1998. Disponível em: http://www.uff.br/saudecoletiva/ professores/merhy/capitulos-10.pdf. Acesso em: 10 jan. 2020. 
MINAYO, Maria Cecília de Souza (org.). Pesquisa social: teoria, método e criatividade. 29. ed. Petrópolis, RJ: Ed. Vozes, 2010.

MINAYO, Maria Cecília de Souza. O desafio do conhecimento: pesquisa qualitativa em saúde. 13. ed. São Paulo: Hucitec, 2013.

MOURÃO, Ana Maria A.; LIMA, Ana M. C. Amoroso; STEPHAN-SOUZA, Auta I.;

OLIVEIRA, Leda M. Leal de. A formação dos trabalhadores sociais no contexto neoliberal: o projeto das residências em Saúde da Faculdade de Serviço Social da Universidade Federal de Juiz de Fora. In: MOTA, A. E. et al. (Org.). Serviço Social e Saúde: formação e trabalho profissional. São Paulo: Cortez, 2006, p. 352-380.

OLIVEIRA, Inajara Carla; CUTOLO, Luiz Roberto Agae. Humanização como Expressão de Integralidade. In: Revista 0 Mundo da Saúde. p. 502-506. São Paulo, 2012. Disponível em: http://www.saocamilosp.br/pdf/mundo_saude/95/13.pdf. Acesso em: 8 jan. 2020.

OLIVEIRA, Magda A.; QUEIRÓS, Cristina; GUERRA, Maria Prista. O Conceito de Cuidador Analisado numa Perspectiva Autopoiética: do caos à autopoiése. In: Revista Psicologia, Saúde \& Doenças. v. 8, n. 2, p. 181-196. Lisboa-PT: Ed. Sociedade Portuguesa de Psicologia da Saúde, 2007. Disponível em: http://www.redalyc.org/articulo.oa?id= 36219037003. Acesso em: 8 mar. 2020.

PEREIRA, Maria de Fátima da Cunha. Cuidadores Informais de Doentes de Alzheimer: sobrecarga física, emocional e social e psicopatologia. Lisboa-PT, 2011. (Dissertação de Mestrado). Disponível em: https://repositorioaberto.up.pt/bitstream/10216/7152/2/Cuidadores\%20Informais\%20de\%20Doentes\% 20de\%20 Alzheimer\%20Sobrecarga\%20Fis.pdf. Acesso em: 8 jan. 2020.

PINHEIRO, Roseni; MATTOS, Ruben Araújo de. Os Sentidos da Integralidade na Atenção e no Cuidado em Saúde. 4. ed. Rio de Janeiro: Cepesc/IMS/Uerj/Abrasco, 2005. 
RAFACHO, Marília; OLIVER, Fátima Corrêa. A Atenção aos Cuidadores Informais/Familiares e a Estratégia de Saúde da Família: contribuições de uma revisão bibliográfica. In: Revista Terapia Ocupacional da Universidade de São Paulo. v. 21, n. 1, 41-50. São Paulo, jan/abr 2010. Disponível em: file:///C:/Users/servi\%C3\%A70\%20social/ Downloads/14084-17062-1-PB\%20(1).pdf. Acesso em: 8 mar. 2020.

ROCHA JÚNIOR, Paulo Roberto; CORRENTE, José Eduardo; HATTOR, Cíntia Harumi; OLIVEIRA, Isadora Maria de; ZANCHETA, Dalise; GALLO, Carla Gelamo; MIGUEL, Juliana Padovesi; GALIEGO, Evelise Trindade. Efeito da capacitação dos cuidadores informais sobre a qualidade de vida de idosos com déficit de autocuidado. Ciênc. Saúde coletiva [online]. v. 16, n. 7, p. 3131-3137, 2011.

SANCHES, leda Cristina Pereira; COUTO, Ingrid Ramos Reis; ABRAHÃO, Ana Lúcia; ANDRADE, Marilda. Acompanhamento Hospitalar: direito ou concessão ao usuário hospitalizado? In: Revista Ciência e Saúde Coletiva, v. 18, n. 1, p. 67-76. Rio de Janeiro: Associação Brasileira de Pós-Graduação em Saúde Coletiva, 2013. Disponível em: http://www.redalyc.org/articulo.oa?id=63025587008. Acesso em: 8 mar. 2020.

SILVA, Alaide Maria Morita Fernandes da. Produção do cuidado em saúde e o Serviço Social. Tese (Doutorado em Serviço Social). Pontifica Universidade Católica de São Paulo. 2013.

SILVER, Heidi J.; WELLMAN, Nancy S. Nutrition education may reduce burden in family caregivers of older adults. Journal of Nutrition Educational and Behavior, v. 34, supplement 1, p. 53-58, 2002.

VASCONCELOS, Ana Maria de. A prática do serviço social: cotidiano, formação e alternativas na área de saúde. São Paulo: Ed. Cortez, 2002. 
VERÍSSIMO, Cristina Maria Figueira; MOREIRA, Isabel Maria Pinheiro Borges. Os Cuidadores Familiares/Informais: Cuidar do doente idoso dependente em domicílio. Pensar Enfermagem, v. 8 n. 1, p. 60-65, 2004.

VIEGAS, Selma Maria da Fonseca; PENNA, Cláudia Maria de Mattos. A construção da integralidade no trabalho cotidiano da equipe saúde da família. Esc. Anna Nery [online]. v. 17, n. 1, p. 133-141, 2013.

ZENI, Paula; CUTOLO, Luiz Roberto. Agea. Abordagem da humanização na formação acadêmica dos cursos de graduação da área da saúde da UNOCHAPECÓ - Avaliação dos Planos Pedagógicos de Cursos. In: Revista Saúde \& Transformação Social. v. 2, n. 1, p. 88-95. Florianópolis, SC, 2011. Disponível em: http://incubadora.periodicos.ufsc.br/index.php/

saudeetransformacao/article/view/1066/1291. Acesso em: 11 mar. 2020.

Enviado: Julho, 2021.

Aprovado: Janeiro, 2022. 